\title{
The Cost of Diabetes-Related Complications: Registry-Based Analysis of Days Absent from Work
}

\author{
Jan Sørensen ${ }^{1}$ and Uffe Jon Ploug ${ }^{2}$ \\ ${ }^{1}$ University of Southern Denmark, J. B. Winsløws Vej 9B, 5000 Odense, Denmark \\ ${ }^{2}$ Novo Nordisk A/S, Vandtårnsvej 114, 2860 Søborg, Denmark \\ Correspondence should be addressed to Jan Sørensen; jas@cast.sdu.dk
}

Received 8 December 2012; Accepted 30 January 2013

Academic Editor: Colin C. Williams

Copyright (c) 2013 J. Sørensen and U. J. Ploug. This is an open access article distributed under the Creative Commons Attribution License, which permits unrestricted use, distribution, and reproduction in any medium, provided the original work is properly cited.

\begin{abstract}
The aim of this study was to estimate the annual number of days absent from work associated with diabetes-related complications. Registry data were obtained for 34,882 individuals aged 18-70 years with hospital-diagnosed diabetes (ICD-10 codes: E10-E14) identified from a large national sample ( $40 \%$ of the Danish population) with 6 years of hospital utilisation data. The occurrence of a complication was defined as a hospital admission with a specified diagnosis or procedure code. Data on sickness episodes with municipal subsidy were retrieved for each individual. Days absent from work attributable to complications were defined as the estimated difference in absence days between individuals with and without the specified complication and were estimated for the first and subsequent years after the initial episode of the recorded complication. Angina pectoris, ischaemic stroke, and heart failure were the three most frequent complications in the population. Heart failure, amputation, renal disease, and peripheral vascular disease were on average associated with more than three-month additional absence from work during the first and subsequent years. Leg ulcers and neuropathy were associated with more days absent from work during the first year than in subsequent years. Diabetes complications are associated with a substantial number of additional days absent from work. The avoidance of these complications would benefit both patients and society.
\end{abstract}

\section{Introduction}

Diabetes is a chronic disease that has a serious impact on health status, duration of life, cost of health care, and social production [1]. Diabetes is associated with a number of longterm health complications, many of which impose additional costs above those associated with the disease itself and thus can be a considerable burden on health care systems [2]. Such complications are likely to incur additional indirect costs to patients, employers, and society due to absence from work caused by sickness days and early retirement.

A US-based analysis of the cost attributable to diabetes estimated an annual cost of 174 billion \$ in 2007. Two-thirds of this cost was related to health care of patients with diabetes and one-third to lost production. The cost of lost production included costs associated with "work day absence" (4\%), "reduced performance at work" (34\%), "permanent disability" (14\%), and "premature mortality" (46\%) [3]. Although the analysis suggested that the production cost related to premature deaths was substantial, the production loss of individuals living with diabetes was also considerable, both for those in employment and those outside the labour market.

Similar findings are likely in Scandinavian countries. A recent Norwegian study found that the health care cost of diabetes accounted for three-quarters of the cost associated with diabetes, while labour market consequences accounted for one-quarter. The latter is possibly a low estimate as the analysis did not include cost related to premature mortality which may be considerable in diabetes [4]. A recent Danish cohort study found that individuals with diabetes have a 1.52.5 times higher mortality in comparison with the general population [5]. Similar increased mortality has also been reported in studies from Sweden and the UK $[6,7]$.

The health care cost of diabetic complications has been investigated in a number of studies. A Swedish study used hospital records of individuals diagnosed with diabetes to 
estimate the annual hospitalisation cost of treating diabetesrelated complications [8]. Complications were recorded according to ICD-10 diagnostic information, and panel data regression models were used to estimate hospital treatment costs during the year of the first complication episode, the year of the second complication episode, and subsequent years. They found that hospital-treated complications in patients with diabetes significantly elevated the treatment cost both in the year the complication occurred and in subsequent years, compared to the cost for people without diabetes. This finding is consistent with other studies (see, e.g., $[9-11])$.

Labour market consequences of illness include days absent from work and reduced job performance due to poor health, reduced labour force participation and reduced earnings capacity due to permanent disabilities, and lost productivity due to premature mortality [3].

The likelihood of being employed was estimated to be $10 \%$ less for men with diabetes in a US cross-sectional study of individuals aged $45+$ years residing in a poor border area of South Texas [12]. Analysis of data from a nationally representative Australian sample showed that diabetes might reduce labour market participation by nearly $4 \%$ for men aged $18-$ 49 years and $12 \%$ for men aged $50-65$ years [9]. A US study focusing on women's labour force participation found that women with diabetes had a $23 \%$ lower probability of working [13], while a Canadian study showed that the likelihood of being in the labour market was $19 \%$ and $17 \%$ lower for men and women with diabetes, respectively [14]. Although these studies provide different assessments of the size of impact, they all indicate that diabetes is associated with substantial negative effects on labour market attachment.

Besides being associated with a lower probability of employment, diabetes may also be associated with lower earnings. A Swedish study using longitudinal data from 19832005 matched individuals with type 1 diabetes with controls of similar age, gender, and municipality at the time of diabetes diagnosis [15]. The study showed that individuals with type 1 diabetes had a considerable decline in future earnings compared with the general population.

Loss of work productivity has been studied using US longitudinal cohort data. Men and women with diabetes were $5 \%$ and $6 \%$, respectively, more likely to have work limitations compared to those without diabetes, and individuals with diabetes had more days off work than those without diabetes [16].

Diabetes thus appears to have a significant impact on labour market attachment and social production. While several studies have assessed loss of production associated with diabetes per se, only few studies have investigated the labour market consequences of diabetic complications although the loss of production associated with diabetes most likely come from complications. In a study of macrovascular comorbidity, the number of work days missed due to illness or injury and the number of days spent in bed due to illness or injury were analysed [17]. After adjustment for a wide range of covariates, the annual work force absence related to macrovascular conditions in individuals with diabetes was estimated at 20 days. A second study looking at peripheral neuropathy complications [18] analysed data on work productivity collected with the Work Productivity and Activity Impairment Questionnaire [19]. Individuals with peripheral neuropathy reported a $13 \%$ higher rate of work impairment than individuals with diabetes without peripheral neuropathy and even higher impairment related to general activities.

Our search of the literature revealed no studies that used health registers to identify individuals with complications or administrative registers to measure labour force absence as a consequence of diabetes-related complications.

The aim of the current study was to assess the potential impact of a range of diabetes-related complications on work production. We used registry data to identify a nationally representative sample of individuals with diabetes and to estimate the annual number of days absent from work due to complications in individuals with diabetes.

\section{Methods}

2.1. Identification of Individuals with Diabetes. The unique Danish person identification number enables researchers to combine individual-level data from different administrative registries, including national hospital records and the municipal sickness benefit register that contains data on absence from work [20]. Several Danish studies have used national registries to identify individuals with diabetes and estimate the prevalence of diabetes (see, e.g., [21, 22]).

The basis for the current analysis was a database of 2.2 million randomly selected Danes representing approximately $40 \%$ of the adult population aged $18-70$ years. From the National Patient Registry (NPR), we obtained data about these individuals' use of hospital care during 1997-2002. From social service statistics, we obtained data on labour market attachment, registered sickness periods, and municipal reimbursement of sickness benefit payments.

In the analysis, we defined diabetes according to the ICD-10 codes E10-E14, that is, the full spectrum of diabetes including the subgroups of insulin-dependent diabetes (E10), non-insulin dependent diabetes (E11), and unspecific diabetes (E14). We included all individuals who had a hospital contact during 1997-2002 either as an outpatient or an inpatient, where diabetes was included in the registry of diagnostic codes. As this part of the analysis was concerned with identifying people with diabetes, we imposed no restrictions on the type of diabetes code and included all types of diagnosesprincipal/first-line diagnosis, secondary diagnoses, and referral diagnoses. If an individual was registered by a hospital doctor as having diabetes at any time during the observation period, then we considered that individual to be diagnosed with diabetes.

The onset of diabetes was registered as the date of the earliest hospital contact for diabetes. Although many patients are initially diagnosed with diabetes by a primary care physician, such diagnosis are not registered in the administrative primary care registries. However, the NPR records the date of the first diabetes-related hospital contact in a treatment series; this variable was used to indicate the date of the first diagnosis. This meant that some individuals were diagnosed 
TABLE 1: Definitions of diabetes-related complications and number of individuals identified.

\begin{tabular}{|c|c|c|c|c|c|c|}
\hline \multirow{2}{*}{$\begin{array}{l}\text { Category } \\
\text { (1) Myocardial infarction }\end{array}$} & \multirow{2}{*}{$\begin{array}{c}\text { ICD-10 codes } \\
\text { I21 }\end{array}$} & \multirow{2}{*}{$\begin{array}{c}\text { Individuals identified } \\
\text { 1997-2002 } \\
4503\end{array}$} & \multicolumn{2}{|c|}{ Occurred in 2001} & \multicolumn{2}{|c|}{ Occurred in 2002} \\
\hline & & & 825 & $18 \%$ & 999 & $22 \%$ \\
\hline (2) Angina pectoris & $\mathrm{I} 20$ & 8382 & 1235 & $15 \%$ & 1186 & $14 \%$ \\
\hline (3) Peripheral vascular disease & $\begin{array}{l}\text { I700, I701, I701, I702, I708, I709, } \\
\text { I739 }\end{array}$ & 4916 & 792 & $16 \%$ & 761 & $15 \%$ \\
\hline (4) Ischaemic stroke & $\begin{array}{c}\text { G450, G458, G459, I678, I61, I63, } \\
\text { I64 }\end{array}$ & 6715 & 1096 & $16 \%$ & 1130 & $17 \%$ \\
\hline (5) Heart failure & $\mathrm{I} 46, \mathrm{I} 50$ & 6672 & 1156 & $17 \%$ & 1338 & $20 \%$ \\
\hline (6) Renal disease & $\begin{array}{l}\text { I12, I13, N18, N019, N052, N055, } \\
\text { N058, N059, N170, N171, N172, } \\
\text { N178, N179 }\end{array}$ & 1573 & 274 & $17 \%$ & 427 & $27 \%$ \\
\hline (7) Uninfected ulcer & L97 & 1893 & 362 & $19 \%$ & 400 & $21 \%$ \\
\hline (8) Infected ulcer & L00, L03, L08 & 1317 & 208 & $16 \%$ & 228 & $17 \%$ \\
\hline (9) Neuropathy & $\begin{array}{l}\text { G560, G561, G562, G563, G564, } \\
\text { G565, G566, G567, G568, G589, } \\
\text { G990, G632, G733, M146, K318H }\end{array}$ & 1869 & 228 & $12 \%$ & 207 & $11 \%$ \\
\hline (10) Amputation & $\begin{array}{c}\text { Procedure codes: KNHQ14, } \\
\text { KNHQ17, KNFQ19, KNGQ19, } \\
\text { KNHQ11 }\end{array}$ & 1448 & 286 & $20 \%$ & 387 & $27 \%$ \\
\hline
\end{tabular}

with diabetes before the observation period (i.e., earlier than 1997).

Only individuals who had (at least once) been hospital diagnosed with diabetes and were alive as of 1 January, 2002 were included. This strategy provided data on 34,882 individuals with diabetes aged 18-70 years. Using a four-year washout period (1997-2000), we identified 7860 individuals who were hospitalised and diagnosed with diabetes for the first time in 2002 (newly diagnosed patients).

2.2. Definition of Complications. Diabetes-related complications were defined according to the diagnostic or operative procedures codes provided in the NPR. Table 1 shows the ICD-10 diagnostic codes and procedure codes used. These definitions were derived from discussion with clinical experts, previous experience with analysis of complications, and inspection of the number of cases in each diagnosis. We omitted rare complications that occurred in less than 200 individuals per year. Table 1 also shows the number of individuals with diabetes who were hospitalised with complications during the whole observation period (19972002) and those hospitalised for complications in 2001 and 2002.

2.3. Absence from Labour Market. Data on socioeconomic status were available for 2002 and included a variable that showed the most frequent labour market status during that year. The codes included retirement due to old age (code 322), early retirement due to sickness (code 321), and early voluntary retirement (an arrangement aimed at people aged 60 years and over; code 323). Other codes indicated employed, unemployed, and under education. We excluded 185 individuals in education (code 310) and 978 outside the work force for other reasons (code 410 and missing). Of the remaining individuals, $28 \%$ were coded as early retirement due to sickness (code 321 ), $17 \%$ as oldage retirement (aged 66-70 years; code 322), 10\% as early voluntary retirement (code 323 ), and $4 \%$ on social benefit (code 330). We assumed that the labour market status of these individuals was constant over the whole year and thus assigned these individuals with 365 absence/sickness days. We assumed that the remaining $42 \%$ of the sample was attached to the labour market and had absence/sickness days as recorded by their local municipality.

At the time of observation, the Danish municipalities were responsible for funding the reimbursement of sickness benefit beyond the first 14 days (later this has been changed to the first 21 days). Each illness episode that satisfies the criteria for reimbursement is recorded in a registry containing information about the type of sickness/absence and the outcome (return to work, continued rehabilitation, or departure from labour market). There is also information on the amount of reimbursement paid to the employer and employee (subsidies), the number of days that subsidies were paid for, and the full number of sickness days (i.e., including the first 14 days of the sickness period where no subsidies are paid). We obtained individual data from this registry for the year 2002 .

In the event that an individual is recorded as having several sickness episodes in one year, these might represent real separate periods of illness but may also be due to the individual having more than one employer (e.g., two part-time jobs) and that subsidies have been paid to all employers for the one illness episode. The data set obtained did not include dates of illness. In the preparation of the data, we aggregated the number of days absent from work for each individual. If the same person had two records with an identical number 
of sickness days, it was assumed that this person had two employers and that subsidies were paid to both. In these cases, the days of sickness were counted only once.

Only absence due to personal illness was included in the analysis (codes 11, 12, 13, 14, 17, and 22). Subsidies and absence relating to pregnancy/childbirth and sabbatical leave were excluded. All observations of days absent from work were truncated at 365 days.

2.4. Analysis. We wanted to obtain estimates of days absent from the labour market due to complications in the first and subsequent years. We used the principle of "attributable cost" [23], which proposes that by comparing the mean cost of exposed individuals (i.e., individuals with a complication) with the mean cost of nonexposed individuals (i.e., individuals without a complication), the observed difference in mean cost can be interpreted as the mean cost attributable to the exposure (i.e., the complication). This principle has been used in many registry-based analyses [20] and was used here to estimate the absence period attributable to particular complications.

For the actual estimation, we used an ordinary regression model where the estimated parameter for the dummy variable for the presence of complication was interpreted as the attributable cost of the complication.

The observed days of absence in 2002 were used as the dependent variable. The interaction variables for dummy variables for periods of 12 months after the first diagnosis (first and subsequent years) and dummy variables for the different complications (present or not) were used as independent variables. We interpreted the estimated period parameter as the average absence period (in days) associated to the particular complication.

We initially undertook the analysis for the whole sample of individuals with diabetes aged 18-70 years. Subsequent analysis included only the sample of individuals who were in the labour market, through the exclusion of individuals registered with early retirement, old age pension, and early voluntary retirement.

We report the number of individuals with and without complications and the average period of sickness for the two groups. From the regression models, we report the estimated mean absence period (days) and 95\% confidence intervals.

\section{Results}

The estimated mean absence periods attributable to different complications are presented in Tables 2 and 3. Table 2 includes the whole sample of people with diabetes alive as of 1 January, $2002(n=34,882)$, while Table 3 includes mean absence periods calculated for those in the workforce only $(n=14,746)$.

The average individual with diabetes was absent from the labour market about 226 calendar days, corresponding to $61 \%$ of a year (Table 2 ). This figure includes both individuals in the labour market and those outside due to sickness or retirement. Individuals with one of the defined complications were absent for longer periods.
In the whole sample, 839 individuals $(2.4 \%)$ were identified with new myocardial infarction in 2002. The average labour market absence attributable to the incidence of myocardial infarction was on average 62 days (95\% CI: 5174).

Of the remaining 34,043 individuals, 1,419 (4.2\%) had been hospitalised with a myocardial infarction between 1997 and 2001. The average labour market absence attributable to complications in these subsequent years was 65 days (95\% CI: 56-74).

Amputation, heart failure, and renal disease are complications that were associated with the longest period of labour market absence in the first year (and subsequent years) after the event, while ulcers and neuropathy were associated with shorter absence. Ischaemic stroke and peripheral vascular disease were associated with longer absence periods in years subsequent to the event.

The prevalence of complications was lower when only individuals still in the labour market were included in the analysis (Table 3). Individuals with diabetes without complications had an average 38 days of absence from work, but this figure increased considerably in the event of diabetes-related complications (e.g., 143 days after amputation). In subsequent years, individuals in the workforce had shorter periods of absence for all complications compared to the sample as a whole.

\section{Discussion}

In this study, we estimated the number of days absent from the labour market associated with serious health complications in individuals with diabetes. The underlying analytical principle of attributable cost was used in a regression model, in which the estimated parameters for complication dummies were interpreted as the mean absence from work due to complications. The difference in absence days was assumed to reflect the additional period of absence related to the complication. We used two samples - one with all individuals aged 18-70 diagnosed with diabetes and one including only individuals attached to the labour market. It is interesting to note that the absence period in the years after the complications was considerably lower in the analysis that includes only individuals in the labour market.

The identification of individuals with diabetes was based on hospital registration of diagnosis (inpatients and outpatients). Individuals who were diagnosed prior to 1997 and had not had a hospital contact coded for diabetes (e.g., where all diabetic management was provided by the general practitioner) would not be identified through this method. However, the six-year washout period should be long enough to capture most individuals with diabetes. Other studies have used different criteria for identifying individuals with diabetes. A previous Danish study used data from both the hospital registry (inpatient and outpatient) and the primary care registry (specific codes for chiropody services and glucose tests provided in the primary care sector) [22]. Other studies have also extracted data from laboratory and prescription databases $[21,24]$. Patients with diabetes could also 


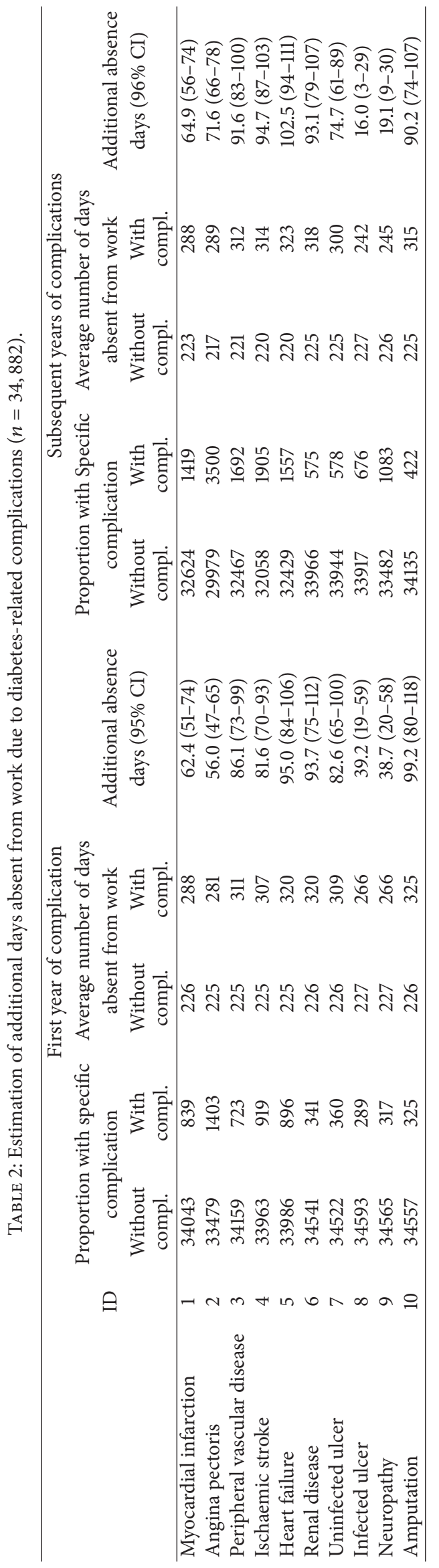




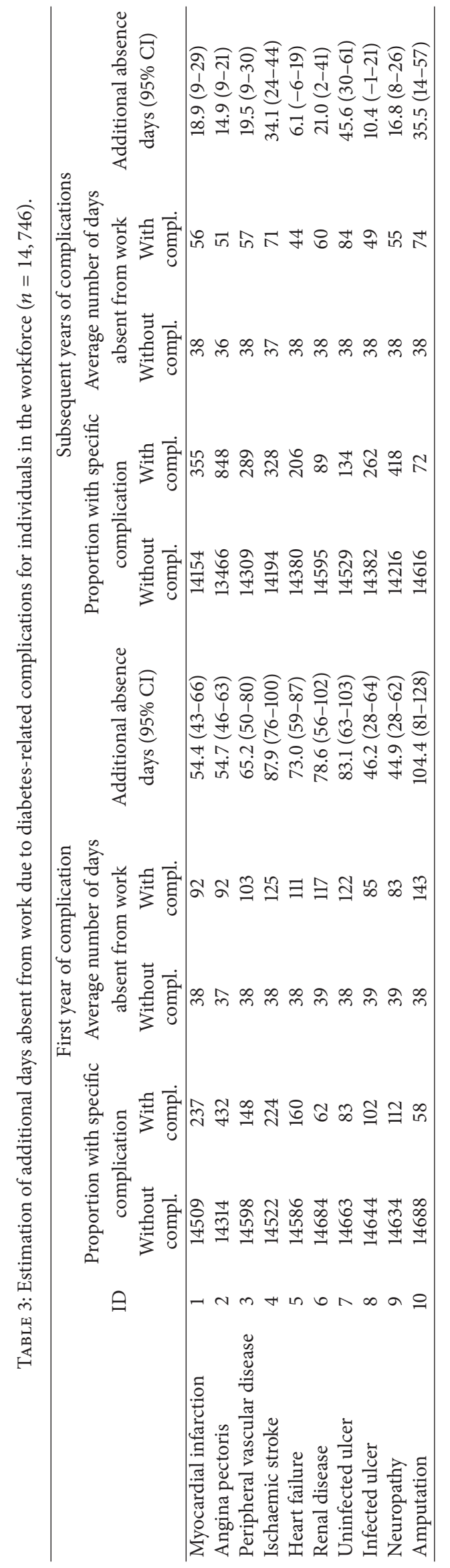


be identified from general practitioner records using the international classification of primary care [25] if access to such data could be established. However, the best approach for future studies is likely to be the national diabetes registry [26].

In defining individuals with diabetes, we did not differentiate between type 1 and type 2 diabetes. This is the result of coding in ICD-10. Diabetes is defined only according to the need for insulin, which would group all type 1 cases with those type 2 cases who required insulin. There are differences in the age distribution of complications between the two types, however, such that people with type 1 diabetes are more likely to experience complications before age 70 . It would thus be useful to analyse the types of diabetes separately in future studies.

In the analysis of work absence, we have included absence for all adults aged 18-70. We assumed that the absence attributable to the diabetes complication would not have arisen if the individual had not experienced the complication, on the assumption that the labour market allowed full employment. That would be the case in situations with staff shortages, but might not be appropriate in times of high unemployment.

We did not have data on type of employment, and this might be expected to influence the opportunities to continue working after the onset of a diabetes-related complication. Also, various social characteristics variables, for example, immigration from nonwestern countries, could have been relevant for the analysis. The need for subsequent analyses to differentiate between individuals who may have a weak or strong labour market attachment is clearly evident, and the lack of such considerations in this analysis may provide a biased impression of the labour market consequences of diabetes-related complications.

The Danish pension age in year 2002 was 67 years (it was later reduced to 65 years in 2004). In our first analysis, we assumed that individuals aged 67-70 years potentially could work, as retirement age is nonmandatory and a longer working life leads to higher annual retirement benefits in subsequent years. In the public sector, however, there is a mandatory retirement age of 70 years. Only individuals in employment were considered in our second analysis.

In contrast to many other studies of production loss due to health problems, we used administrative data on absence from work. The majority of these data are registered in connection with some form of money transfer either to the employer as subsidies or direct payment as sickness pay or social pension. We have thus avoided imprecision in reporting and recalling bias that can affect the quality of survey studies. Earlier studies of sickness periods using these administrative registers were biased, as public employers were not required to register their employees' absences, as no subsidies were paid to them. This has now been changed, however, so also absences of public sector employees are included in the registry. There may be some systematic omissions in the registry data, however. According to the regulations at the time of data collection (2002), employers had to finance sickness absence of less than 14 consecutive days. That means that short absences due to minor illnesses were not included in the registry. The influence of this underreporting of work absence is difficult to assess, as we do not know its extent, the causative health problem, or whether the rate of short-term illness differs for those in or out of the workforce.

We have focused exclusively on absence from the labour market. Other production costs associated with diabetesrelated complications could include lower productivity due to presenteeism and premature death [27]. Presenteeism arises when sick individuals attend work and have lower than normal productivity. Presenteeism is usually assessed in studies based on surveys and cannot be assessed using registry data. Production loss associated with premature death is usually estimated using either the human capital method or the friction method, which assess the value of production that would have occurred if the individual had not died. Such estimations are reasonably straightforward using registrybased data on mortality and value of production (gross salary).

People with diabetes have an elevated mortality risk. Current national data suggest that individuals with diabetes have a relative risk ratio of $1.5-2.5$, indicating a $60-150 \%$ increased risk of premature death $[5,26]$. We have not taken mortality into account, and thus the estimates of labour market absence may be underestimated.

In the current study, absence from work has been estimated for each of the defined complications separately, thus in effect assuming independency of complications. That is a simplification in the analysis that might either under- or overestimate the duration of absence. We have not found any evidence to determine whether the effect of diabetes complications should be treated as additive or multiplicative.

Treatment of renal failure includes dialysis, but the data codes for this activity were not available from the hospital registration system. Psychiatric complications were not included as our data material only related to the somatic hospital service. A psychiatric hospital registry does exist, however, that records health services provided by the psychiatric health care sector. Other complications not requiring hospital admission or outpatient care were also disregarded, including minor complications that are usually managed within the family or by the general practitioner or other primary care providers, such as most hypoglycaemic episodes.

\section{Conclusion}

Existing studies have established that diabetes leads to significant indirect costs in the form of production loss, sick days, and earlier departure from the workforce. The aim of this study was to use individual-level data from national registries to assess the potential impact of diabetes-related complications on work absence.

Cardiovascular problems were the most common complications registered (the three most frequent being angina pectoris, ischaemic stroke, and heart failure). Several of the complications investigated were found to lead to an average work absenteeism of over three months.

These results indicate that a reduction in the incidence of diabetes-related complications has the potential not only to improve patient morbidity and quality of life, but also to reduce workforce absenteeism. 


\section{Acknowledgments}

The study was initiated and financially supported by Novo Nordisk Scandinavia AB. U. J. Ploug is an employee of and shareholder in Novo Nordisk A/S. Editorial assistance by Claire Gudex is gratefully acknowledged.

\section{References}

[1] L. Ettaro, T. J. Songer, P. Zhang, and M. M. Engelgau, "Costof-illness studies in diabetes mellitus," PharmacoEconomics, vol. 22, no. 3, pp. 149-164, 2004.

[2] B. Leese, "The costs of diabetes and its complications," Social Science and Medicine, vol. 35, no. 10, pp. 1303-1310, 1992.

[3] American Diabetes Association, "Economic costs of diabetes in the U.S. in 2007," Diabetes Care, vol. 31, no. 3, pp. 596-615, 2008.

[4] O. Solli, T. Jenssen, and I. S. Kristiansen, "Diabetes: cost of illness in Norway," BMC Endocrine Disorders, vol. 10, article 15, 2010.

[5] L. J. Hansen, N. De Fine Olivarius, and V. Siersma, "16-year excess all-cause mortality of newly diagnosed type 2 diabetic patients: a cohort study," BMC Public Health, vol. 9, article 400, 2009.

[6] P. Wennberg, O. Rolandsson, L. Jerdén et al., "Self-rated health and mortality in individuals with diabetes mellitus: prospective cohort study," BMJ Open, vol. 2, no. 1, Article ID e000760, 2012.

[7] H. E. Mulnier, H. E. Seaman, V. S. Raleigh, S. S. SoedamahMuthu, H. M. Colhoun, and R. A. Lawrenson, "Mortality in people with type 2 diabetes in the UK," Diabetic Medicine, vol. 23, no. 5, pp. 516-521, 2006.

[8] U. G. Gerdtham, P. Clarke, A. Hayes, and S. Gudbjornsdottir, "Estimating the cost of diabetes mellitus-related events from inpatient admissions in sweden using administrative hospitalization data," PharmacoEconomics, vol. 27, no. 1, pp. 81-90, 2009.

[9] P. Clarke, J. Leal, C. Kelman, M. Smith, and S. Colagiuri, "Estimating the cost of complications of diabetes in Australia using administrative health-care data," Value in Health, vol. 11, no. 2, pp. 199-206, 2008.

[10] J. A. O’Brien, L. A. Shomphe, P. L. Kavanagh, G. Raggio, and J. Jaime Caro, "Direct medical costs of complications resulting from type 2 diabetes in the U.S.," Diabetes Care, vol. 21, no. 7, pp. 1122-1128, 1998.

[11] J. J. Caro, A. J. Ward, and J. A. O'Brien, "Lifetime costs of complications resulting from type 2 diabetes in the U.S.", Diabetes Care, vol. 25, no. 3, pp. 476-481, 2002.

[12] H. S. Brown, J. A. Pagán, and E. Bastida, "The impact of diabetes on employment: genetic IVs in a bivariate probit," Health Economics, vol. 14, no. 5, pp. 537-544, 2005.

[13] T. Minor, "The effect of diabetes on female labor force decisions: new evidence from the National Health Interview Survey," Health Economics, vol. 20, no. 12, pp. 1468-1486, 2010.

[14] E. Latif, "The impact of diabetes on employment in Canada," Health Economics, vol. 18, no. 5, pp. 577-589, 2009.

[15] K. Steen Carlsson, M. Landin-Olsson, L. Nyström et al., "Longterm detrimental consequences of the onset of type 1 diabetes on annual earnings-evidence from annual registry data in 19902005," Diabetologia, vol. 53, no. 6, pp. 1084-1092, 2010.

[16] K. Tunceli, C. J. Bradley, D. Nerenz, L. K. Williams, M. Pladevall, and J. E. Lafata, "The impact of diabetes on employment and work productivity," Diabetes Care, vol. 28, no. 11, pp. 2662-2667, 2005.
[17] A. Z. Fu, Y. Qiu, L. Radican, and B. J. Wells, "Health care and productivity costs associated with diabetic patients with macrovascular comorbid conditions," Diabetes Care, vol. 32, no. 12, pp. 2187-2192, 2009.

[18] M. daCosta DiBonaventura, J. C. Cappelleri, and A. V. Joshi, "A longitudinal assessment of painful diabetic peripheral neuropathy on health status, productivity, and health care utilization and cost," Pain Medicine, vol. 12, no. 1, pp. 118-126, 2011.

[19] M. C. Reilly, A. S. Zbrozek, and E. M. Dukes, “The validity and reproducibility of a work productivity and activity impairment instrument," PharmacoEconomics, vol. 4, no. 5, pp. 353-365, 1993.

[20] M. Kruse and T. Christiansen, "Register-based studies of healthcare costs," Scandinavian Journal of Public Health, vol. 39, no. 7, pp. 206-209, 2011.

[21] J. K. Kristensen, T. B. Drivsholm, B. Carstensen, M. StedingJessen, and A. Green, "Validation of methods to identify known diabetes on the basis of health registers," Ugeskrift for Laeger, vol. 169, no. 18, pp. 1687-1692, 2007.

[22] T. B. Drivsholm, K. Frederiksen, N. de Fine Olivarius, B. Ødegaard, and J. K. Kristensen, "The prevalence of diabetes in Denmark. Development of a method for a registry-based assessment," Ugeskrift for Laeger, vol. 165, no. 29, pp. 2887-2891, 2003.

[23] G. Shillinglaw, "The concept of attributable cost," Journal of Accounting Research, vol. 1, no. 2, pp. 73-85, 1963.

[24] L. A. Thomsen, J. Gundgaard, B. Søndergaard, A. Melander, and J. Sørensen, "Can Danish health care registries provide data for specific pDRA indicators in diabetes?" Ugeskrift for Laeger, vol. 169, no. 33, pp. 2637-2642, 2007.

[25] H. Schroll, H. Støvring, A. Houmand, and J. Kragstrup, "Estimating incidence and prevalence of episodes of care in general practice," Scandinavian Journal of Primary Health Care, vol. 22, no. 1, pp. 60-64, 2004.

[26] N. B. o. Health, “The national diabetes registry 2007," in Nye tal fra Sundhedsstyrelsen2009.

[27] A. Brooks, S. E. Hagen, S. Sathyanarayanan, A. B. Schultz, and D. W. Edington, "Presenteeism: critical issues," Journal of Occupational and Environmental Medicine, vol. 52, no. 11, pp. 1055-1067, 2010. 

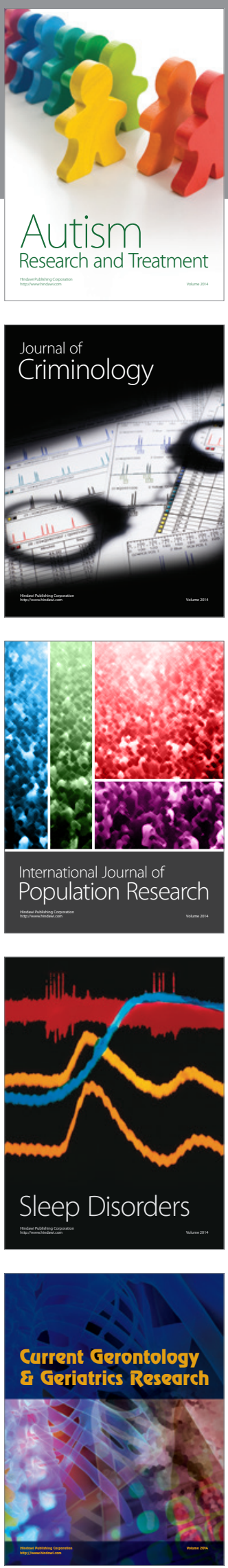
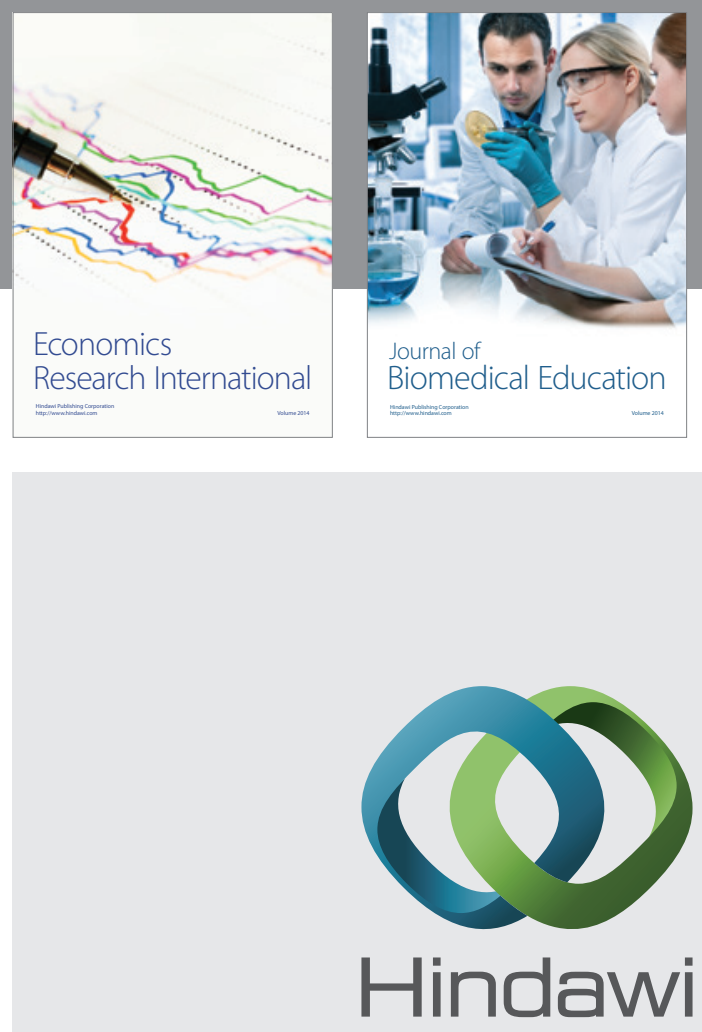

Submit your manuscripts at

http://www.hindawi.com
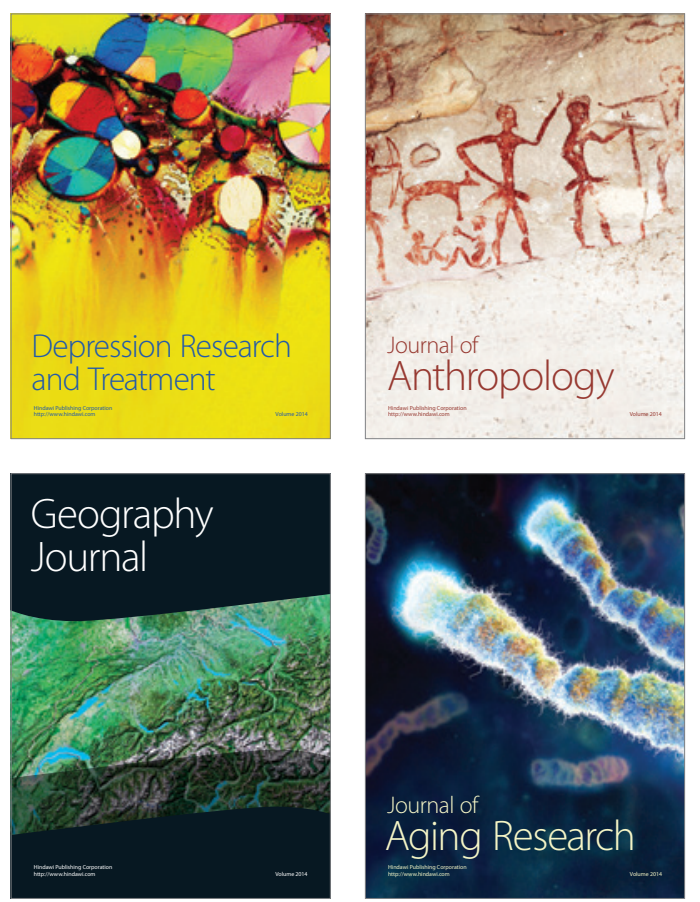
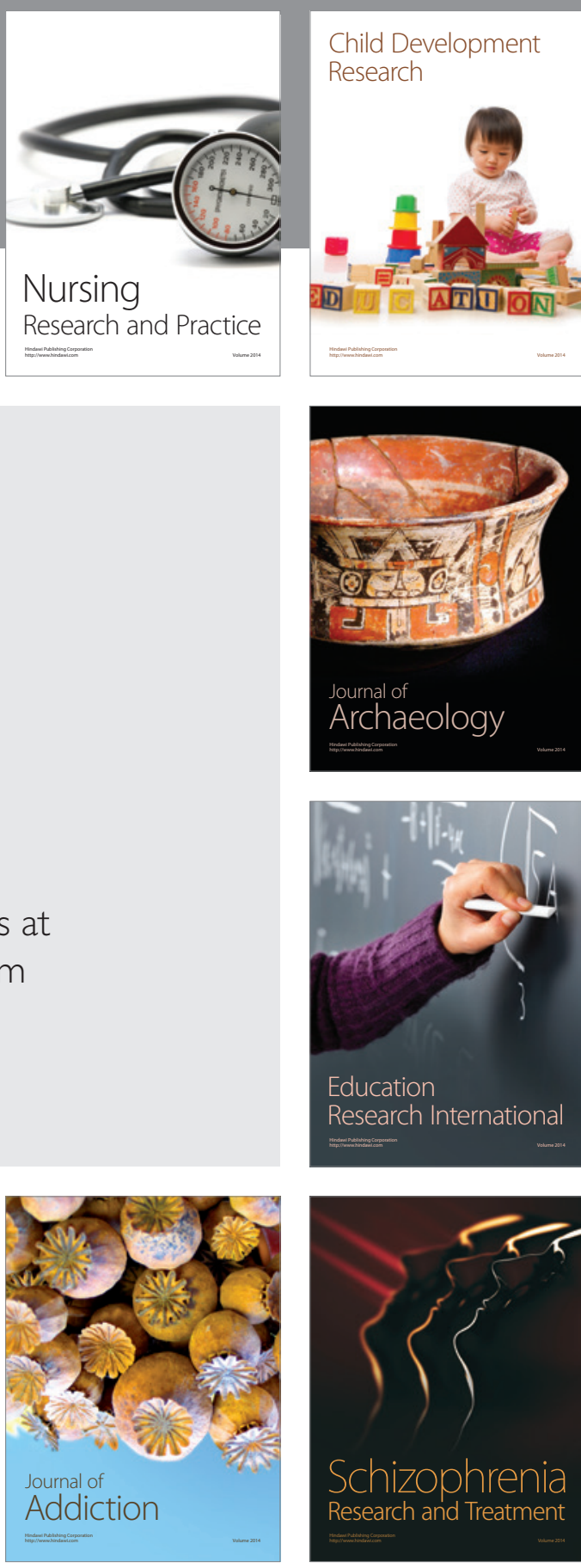

(D)
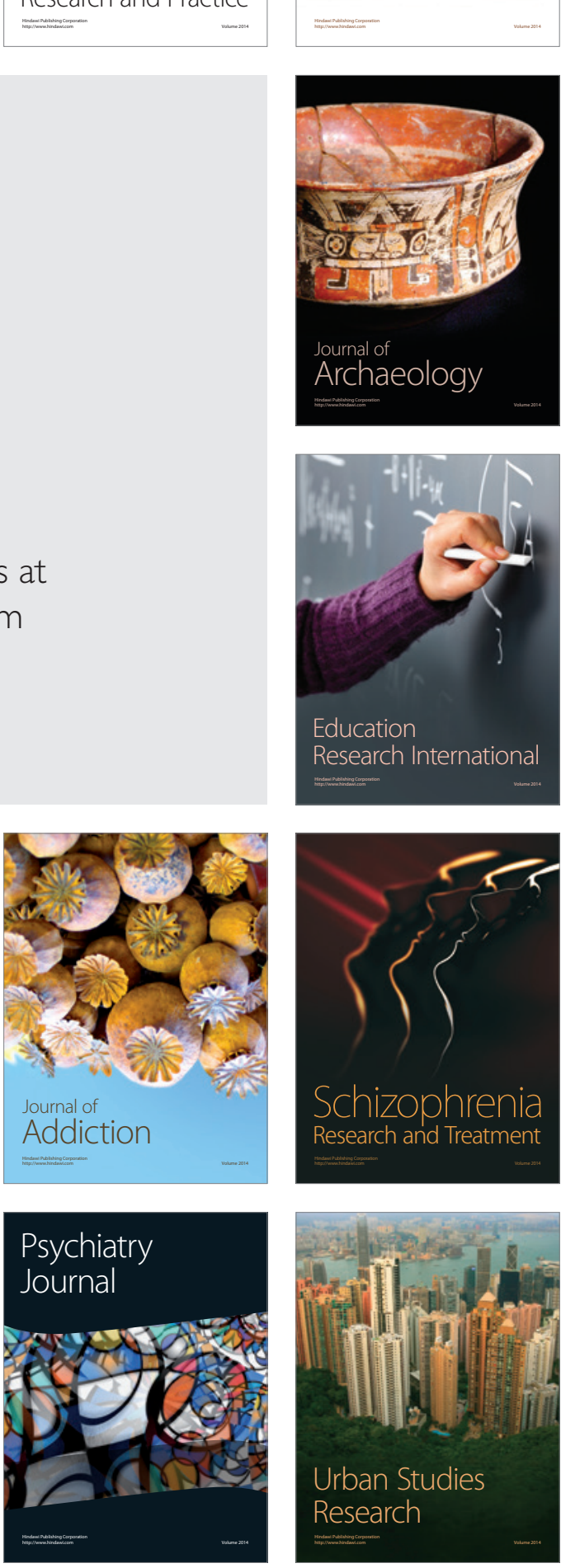